\title{
DESENVOLVIMENTO DA VINAGREIRA (Hibiscus sabdariffa Linn.) EM FUNÇÃO DE SEIS NÍVEIS DE SALINIDADE DA ÁGUA DE IRRIGAÇÃO
}

\author{
M. A. de L. SALES ${ }^{1}$, F. J. C. MOREIRA ${ }^{2}$, W. M. ELOI ${ }^{3}$, A. de A. RIBEIRO ${ }^{4}$ \\ Universidade Estadual Paulista ${ }^{1}$, Instituto Federal de Educação, Ciência e Tecnologia do Ceará2,3,4 \\ franze.moreira@ifce.edu.br ${ }^{1}$
}

Artigo submetido em 26/08/2013 e aceito em 24/06/2019

DOI: $10.15628 /$ holos.2019.1602

\begin{abstract}
RESUMO
A qualidade da água é um dos fatores que ocasionam efeito negativo sobre o desenvolvimento e a produção das culturas. Para a utilização da água com elevados teores de sais solúveis na agricultura, deve-se utilizar um manejo racional, de modo que a cultura desenvolva a produtividade esperada. Em vista disso, este ensaio teve o objetivo de avaliar o desenvolvimento de vinagreira em função de seis níveis de salinidade da água de irrigação. $O$ trabalho foi realizado no período de novembro de 2010 a janeiro de 2011, em casa de vegetação do IFCE - Campus de Sobral. O ensaio foi disposto no delineamento inteiramente casualizado (DIC), em esquema fatorial $6 \times 8$, com parcelas
\end{abstract}

subdivididas no tempo, sendo seis concentrações salinas da água de irrigação $\left(0,27 \mathrm{dS} \mathrm{m} \mathrm{m}^{-1}\right.$ - testemunha; 1,$5 ; 2,5$; 3,$5 ; 4,5$ e $\left.5,5 \mathrm{dS} \mathrm{m}^{-1}\right)$, e oito épocas de avaliação $(0,7$, $14,21,28,35,42$ e 49 dias após o transplante), com cinco repetições cada. De posse dos resultados, verificase que a elevação da concentração de sais na água de irrigação, ocasionou uma redução no desenvolvimento inicial das mudas de vinagreira, onde em alguns tratamentos resultou na morte de plantas. Chegando a conclusão que, a diferentes níveis de salinidade na água de irrigação, afetam negativamente o desenvolvimento da cultura.

PALAVRAS-CHAVE: Estresses abióticos. Hibiscus sabdariffa. Qualidade fisiológica. Tolerância.

\section{DEVELOPMENT OF VINEGAR (Hibiscus sabdariffa Linn.) ACCORDING TO SIX LEVELS OF SALINITY OF IRRIGATION WATER}

\section{ABSTRACT}

Water quality is one of the factors that have a negative effect on the development and production of crops. For the use of water with high levels of soluble salts in agriculture, a rational management must be used, so that the crop develops the expected productivity. Therefore, the objective of this experiment was to evaluate the development of vinegar as a function of six levels of irrigation water salinity. The work was carried out from November 2010 to January 2011, in the greenhouse of the IFCE - Sobral Campus. The experiment was arranged in a completely randomized design (DIC), in a $6 \times 8$ factorial scheme, with subdivided plots in time, with six salt concentrations of irrigation water $(0.27 \mathrm{dS}$ $\mathrm{m}^{-1}$ - control, 1.5, 2, 5, 3.5, 4.5 and $5.5 \mathrm{dS} \mathrm{m}^{-1}$ ), and eight evaluation periods $(0,7,14,21,28,35,42$ and 49 days after transplantation), with five replicates. The results showed that the increase in the concentration of salts in the irrigation water caused a reduction in the initial development of vinegar seedlings, where in some treatments resulted in the death of plants. We conclude that, at different levels of salinity in irrigation water, they negatively affect the development of the crop.

KEYWORDS: Abiotic stresses, Hibiscus sabdariffa, Physiological quality. Tolerance. 


\section{INTRODUÇÃO}

Apesar do planeta Terra ser constituído de aproximadamente $70 \%$ de água, somente uma pequena porcentagem está disponível para as diversas atividades humanas. E dessas atividades, a agricultura irrigada é a que consome mais água, cerca de $70 \%$ de todo a água utilizada no mundo, são gastos para esse fim (FAO, 2011).

A salinidade da água é um dos fatores que ocasionam efeito negativo no desenvolvimento das culturas e afetam a produção, visto que a água é constituinte dos tecidos vegetais, chegando até mesmo a constituir mais de $90 \%$ de algumas plantas; desta forma para a utilização da água de qualidade inferior na agricultura, deve-se utilizar um manejo racional, através de alternativas economicamente viáveis, de modo que a cultura desenvolva a produtividade esperada (MEDEIROS, SILVA, SARMENTO, \& BARROS, 2007).

Normalmente, em áreas irrigadas o problema de salinidade surge quando os sais dissolvidos na água de irrigação provocam um aumento da tensão total de retenção da água no solo, reduzindo, assim a disponibilidade para as plantas (MELLO, 2009).

A salinidade afeta tanto o crescimento das plantas como a produção e qualidade do produto, se manifestando principalmente na redução da população e desenvolvimento das culturas, com sintoma similar ao causado por estresse hídrico. A acumulação gradativa de sais solúveis no solo, principalmente na zona das raízes, compromete o crescimento das plantas, porque reduz o potencial osmótico da solução do solo, provocando estresse hídrico, toxicidade e desordens nutricionais das plantas, além de afetar os processos fisiológicos e as reações bioquímicas (FREIRE, SOUSA FILHO, SOUTO, \& ARAÚJO, 2010).

A concentração de sais nas áreas do semiárido nordestino se altera bastante de um local para outro. Um dos principais problemas para o cultivo em regiões áridas e semiáridas é a salinidade que faz com que a população final de plantas no campo seja variável, interferindo desde o processo germinativo até a produção (LIRA, ELOI, SALES, RIBEIRO, \& NOGUEIRA, 2011).

A resposta das culturas aos sais presentes na água de irrigação e/ou no solo é variada, pois diversos fatores genéticos, fisiológicos e climáticos contribuem para a maior ou menor sensibilidade da espécie, desde as mais tolerantes como o algodão até mais sensíveis como a maioria das hortaliças (GHEYI, DIAS, \& LACERDA, 2010), sendo necessários estudos que caracterizem o comportamento das mesmas (SALES, ELOI, RIBEIRO, SALES, \& NOGUEIRA, 2011b).

A vinagreira (Hibiscus sabdariffa L.) pertencente à Família Malvaceae, é originária da Índia, do Sudão e da Malásia, sendo posteriormente levada para a África Oriental e países da América Central onde se adaptou em regiões tropicais e subtropicais (MARTINS, 1985). No Brasil, a vinagreira foi introduzida provavelmente através do tráfico de escravos (CARDOSO, 1997).

Espécie autógama (MARTINS, 1985), bienal ou perene, ereta ou de crescimento disperso (LORENZI \& SOUZA, 2000). Por se tratar de uma planta adaptada ao clima quente, se 
desenvolve bem em temperatura superior a $21^{\circ} \mathrm{C}$ e $35^{\circ} \mathrm{C}$, cultivada em uma ampla faixa de condições ambientais. Porém, as regiões quentes e com precipitações anuais entre $800 \mathrm{~mm}$ e $1.600 \mathrm{~mm}$ bem distribuídas são mais adequadas para seu cultivo (MARTINS, 1985).

Também conhecida como rosela, azedinha, quiabo azedo, dentre outros, a vinagreira é uma das espécies consideradas como subutilizadas no Brasil, porém, com grande potencial de produção uma vez que as diferentes partes da planta têm várias utilidades como hortaliça, medicinal e ornamental, rica em vitaminas A e B1 e em ácidos cítrico, málico e tartárico, sendo os cálices a parte mais consumida da planta (CASTRO et al., 2004). Sobota, Pinho e Oliveira (2016) informa que o chá do cálice de hibisco é muito consumido pela população em geral, pois possui propriedades terapêuticas, com efeitos comprovados, são benéficos à saúde. A espécie detém características que lhe conferem utilidades para artesanato, alimento humano, cordoaria e cosméticos, fungicida, inseticida, medicinal, ornamental, para papel, tinturaria dentre outros. Para Silva, Wiest e Carvalho (2016), informam que as flores são comestíveis não convencionais na alimentação alternativa, cujo consumo deve ser estimado, informando que o consumo tende a aumentar futuramente, sendo necessários estudos das alterações e interações específicas.

Estudos tem comprovado o uso do hibisco como agente diurético, uricosúrico, antimicrobiano, leve laxante, sedativo, anti-hipertensivos, antitússico e também na diminuição dos níveis de lipídios totais, colesterol e triglicérides, no tratamento gastrointestinal e de pedra nos rins, assim como para tratar danos no fígado e efeitos da embriaguez. Mais recentemente, há indicativo de que o hibisco parece agir como antioxidante, antimutagênico, antitumoral e antileucêmico (VIZZOTO \& PEREIRA, 2008).

Posto isto, o presente trabalho objetiva avaliar os efeitos de diferentes níveis de salinidade da água de irrigação no desenvolvimento da vinagreira.

\section{MATERIAL E MÉTODOS}

A pesquisa foi realizada na casa de vegetação do Instituto Federal de Educação, Ciência e Tecnologia do Ceará - IFCE, Campus de Sobral, localizado na cidade de Sobral - CE, com coordenadas geográficas $\left(03^{\circ} 40^{\prime} \mathrm{S}\right.$ e $\left.40^{\circ} 14^{\prime} \mathrm{W}\right)$. O clima da cidade é tropical quente semiárido com pluviometria média de $854 \mathrm{~mm}$, temperatura média de 30 으 e a altitude de 70 metros.

O experimento estudou os efeitos dos diferentes níveis de salinidade da água de irrigação ( $T_{1}=$ testemunha $-0,27 \mathrm{dS} \mathrm{m}^{-1} ; \mathrm{T}_{2}=1,5 \mathrm{dS} \mathrm{m}^{-1} ; \mathrm{T}_{3}=2,5 \mathrm{dS} \mathrm{m}^{-1} ; \mathrm{T}_{4}=3,5 \mathrm{dS} \mathrm{m}^{-1} ; \mathrm{T}_{5}=$ $4,5 \mathrm{dS} \mathrm{m}^{-1} \mathrm{e} \mathrm{T}_{6} 5,5 \mathrm{dS} \mathrm{m}^{-1}$ ), sobre o desenvolvimento inicial de plantas de vinagreira.

Os diferentes níveis de salinidade foram encontrados com a relação entre a condutividade elétrica da solução (CEs) e os totais de sais dissolvidos, nas proporções desejadas, utilizou-se como referência a equação proposta por Richards (1954), apresentada na equação (1):

$$
C=C E s \times 640
$$


em que: $\mathrm{C}=$ concentração dos sais, $\mathrm{mg} \mathrm{L}^{-1} ; \mathrm{CEs}=$ condutividade elétrica da solução, $\mathrm{dS}$ $\mathrm{m}^{-1}$.

Para este experimento, desde a semeadura foi utilizada água com diferentes níveis de salinidade na irrigação. Em que estas foram adquiridas artificialmente através da adição de sal refinado iodado, utilizando-se da Equação 1 para obter os diferentes níveis de salinidade na água de irrigação, em que estes visam simular diversos estágios de salinização, possivelmente encontrados quando detectado o problema pelos agricultores. O estudo com estes níveis possibilitou verificar os efeitos da salinidade na redução do desenvolvimento inicial das plantas da cultura estudada.

A semeadura ocorreu no dia 19 de setembro de 2011, aos 38 dias, cinco plantas de cada tratamento foram transplantados para vasos com $10,0 \mathrm{Kg}$ de substrato, composto de uma mistura de terra, esterco e composto orgânico na proporção 1:1:1 (v:v:v). As plantas continuaram sendo irrigadas com as mesmas concentrações salinas por mais 49 dias. Nestas plantas, com o intuito de se acompanhar o desenvolvimento inicial das plantas, mensuraramse as seguintes variáveis: altura da planta, número de folhas definitivas, área da planta, diâmetro do caule, número de hastes, comprimento radicular, peso seco aéreo e radicular, condutividade elétrica do substrato e potencial osmótico.

O delineamento estatístico adotado foi o inteiramente casualizado (DIC), em esquema fatorial $6 \times 8$, com parcelas subdivididas no tempo, sendo seis concentrações salinas da água de irrigação ( $T_{1}=$ testemunha - 0,17; $T_{2}=1,5 \mathrm{dS} \mathrm{m}{ }^{-1} ; \mathrm{T}_{3}=2,5 \mathrm{dS} \mathrm{m^{-1 }} ; \mathrm{T}_{4}=3,5 \mathrm{dS} \mathrm{m}^{-1} ; \mathrm{T}_{5}=4,5 \mathrm{dS}$ $\mathrm{m}^{-1}$ e $\left.\mathrm{T}_{6}=5,5 \mathrm{dS} \mathrm{m}^{-1}\right)$, e oito épocas de avaliação $(0,7,14,21,28,35,42$ e 49 dias após o transplante).

Estas variáveis foram coletadas semanalmente, com auxílio de régua graduada em centímetro e paquímetro digital de $150 \mathrm{~mm}$ e $0,01 \mathrm{~mm}$ de precisão. Aos 49 dias após o transplantio, fez-se a avaliação final do experimento, na qual coletou-se a parte área e sistema radicular de cada planta para a obtenção da massa seca. As mesmas foram acondicionadas em sacos de papel tipo Kraft, individualmente, e postas para secar em estufa a $105 \pm 3{ }^{\circ} \mathrm{C}$, com circulação forçada de ar, pelo período de 24 horas. Passado este período, as amostras foram retiradas, postas para esfriar e pesadas em balança digital com precisão de 0,0001 g.

A área da planta foi obtida pelo produto da área das folhas, em cada tratamento, multiplicado pelo número de folhas existentes na planta.

Para o cálculo da área da folia foram escolhidas duas folhas em cada planta, totalmente desenvolvidas, em cada época de avaliação semanal, totalizando 10 folhas em cada tratamento. As folhas verdes, logo após a medição, eram desenhadas em uma folha de papel milimetrado para o cálculo da área.

A área da folha $(\mathrm{AF})$ foi calculada como o produto das duas dimensões, comprimento (C) e largura (L), o comprimento foi definido como a distância entre o ponto de inserção do pecíolo no limbo foliar e a extremidade oposta da folha e a largura como a maior dimensão perpendicular ao eixo do comprimento, e um fator de forma "f", como a seguir: 


$$
A f=f \times C \times L
$$

O fator de forma "f" foi determinado pela análise de regressão simples entre a área de uma amostra de folhas, de cada avaliação e o produto de suas dimensões. Nesse caso, a reta ajustada ao conjunto de dados possui uma equação do tipo $Y=b . x$, em que "b" corresponde ao fator "f", determinado para obtenção da área foliar real.

Para tanto, foram determinados e avaliados dois valores " $\mathrm{f}$ ", um para as folhas iniciais, cordiformes e outro para as folhas lobadas, que se mantiveram com esta forma até a última avaliação, independente do estádio fenológico em que se encontrava a planta.

Ao término do experimento foi realizada a leitura da condutividade elétrica do substrato, para assim calcular o potencial osmótico. Por isso foi avaliado o potencial osmótico do solo, de acordo com a equação abaixo (3):

$$
\Psi 0 \approx-0,36 \times C E
$$

em que: $\Psi 0$ - potencial osmótico, atm; CE - condutividade elétrica, dS $\mathrm{m}^{-1}$.

Os dados obtidos foram tabulados e as médias calculadas no programa Microsoft Excel $2010^{\circ}$. Depois disso, foram submetidos à análise de variância pelo programa Assistat 7.6 beta.

\section{RESULTADOS E DISCUSSÕES}

\subsection{Altura da planta}

A salinidade afetou a altura de plantas nos tratamentos avaliados conforme observado na Tabela 1.

Tabela 1: Altura das plantas de vinagreira submetidas a diferentes níveis de salinidade da água de irrigação. Sobral, CE, IFCE - Campus de Sobral, 2019.

\begin{tabular}{ccccccc}
\hline \multicolumn{7}{c}{ Níveis de salinidade (dS $\left.\mathbf{~}^{\mathbf{- 1}}\right)$} \\
\hline $\mathbf{D A T}$ & T1 (0,27) & T2 (1,5) & T3 (2,5) & T4 (3,5) & T5 (4,5) & T6 (5,5) \\
\hline $\mathbf{0}$ & $7,7 \mathrm{aBC}$ & $6,6 \mathrm{abBC}$ & $6,5 \mathrm{bcBC}$ & $5,0 \mathrm{cdBC}$ & $4,9 \mathrm{bcBC}$ & $4,1 \mathrm{Dbc}$ \\
$\mathbf{7}$ & $9,7 \mathrm{aAB}$ & $9,4 \mathrm{abAB}$ & $8,0 \mathrm{bcAB}$ & $7,8 \mathrm{cdAB}$ & $7,0 \mathrm{bcAB}$ & $6,5 \mathrm{dAB}$ \\
$\mathbf{1 4}$ & $11,6 \mathrm{aAB}$ & $10,1 \mathrm{abAB}$ & $9,1 \mathrm{bcAB}$ & $7,1 \mathrm{cdAB}$ & $7,6 \mathrm{bcAB}$ & $5,7 \mathrm{dAB}$ \\
$\mathbf{2 1}$ & $16,6 \mathrm{aA}$ & $14,0 \mathrm{abA}$ & $12,0 \mathrm{bcA}$ & $9,8 \mathrm{cdA}$ & $10,0 \mathrm{bcA}$ & $8,3 \mathrm{dA}$ \\
$\mathbf{2 8}$ & $20,4 \mathrm{aAB}$ & $18,1 \mathrm{abAB}$ & $15,4 \mathrm{bcAB}$ & $13,1 \mathrm{cdAB}$ & $12,7 \mathrm{bcAB}$ & $11,8 \mathrm{dAB}$ \\
$\mathbf{3 5}$ & $21,6 \mathrm{aCD}$ & $23,1 \mathrm{abCD}$ & $21,5 \mathrm{bcCD}$ & $0,0 \mathrm{cdCD}$ & $13,9 \mathrm{bcCD}$ & $0,0 \mathrm{dCD}$ \\
$\mathbf{4 2}$ & $24,1 \mathrm{aD}$ & $25,4 \mathrm{abD}$ & $24,1 \mathrm{bcD}$ & $0,0 \mathrm{cdD}$ & $17,5 \mathrm{bcD}$ & $0,0 \mathrm{dD}$ \\
$\mathbf{4 9}$ & $28,2 \mathrm{aCD}$ & $29,6 \mathrm{abCD}$ & $29,1 \mathrm{bcCD}$ & $0,0 \mathrm{cdCD}$ & $21,0 \mathrm{bcCD}$ & $0,0 \mathrm{dCD}$ \\
\hline
\end{tabular}

Médias seguidas pela mesma letra maiúscula na coluna e minúscula na linha não diferem entre si pelo teste de Tukey ao nível de $5 \%$ de probabilidade. 
Nos valores médios de alturas das plantas em centímetros em cada tratamento, 00, 07, $14,21,28,35,42$ e 49 DAT (dias após o transplantio) observa-se que pelo teste de tukey houve diferença significativa em nível de $5 \%$ de probabilidade entre os tratamentos.

A vinagreira apresentou uma redução na primeira semana de $47 \%$ entre o T1 e o T6, enquanto que nas três últimas semanas essa redução foi de $100 \%$, pois o T6 não apresentou resultados finais, visto que as plantas não sobreviveram, o que também foi observado no T4, fato ocorrido devido ao excesso de sais. Comparando o T1 ao T5 na primeira e na última semana, depara-se com uma redução da altura de respectivamente 36 e $26 \%$, mostrando que esta cultura é mais sensível no início do seu desenvolvimento, pois neste período a diferença de altura entre as mudas eram maiores, e com o passar do tempo em que a planta vai se desenvolvendo esta diferença vai ficando menor. Bernardo, Soares e Mantovani (2006) tem uma explicação para o ocorrido, de acordo com estes autores conforme a água do solo evapora, aumenta a concentração de sais na superfície do solo. E como a cada irrigação está aplicando mais sais, tem um acumulo de sais na superfície do solo, trazendo prejuízos para a cultura.

Em um trabalho realizado por Freire et al. (2010), foi observado que houve uma redução das plantas de Nim à proporção que a salinidade do solo aumentou, atingindo ao final do experimento uma redução de $20 \%$ na sua altura. Resultado semelhante foi observado por Silva, Nascimento, Tanan, Oliveira e Lima (2017), em que estes autores observaram uma redução na altura da cultura de alface crespa na orde de $54,65 \%$, isso quando se compara o tratamento controle com o tratamento com $16 \mathrm{dS} \mathrm{m}^{-1}$ da água de irrigação. Para Dias, Duarte, Medeiros e Teles Filho (2006), em um trabalho realizado com salinidade na cultura do melão os efeitos da salinidade sobre a altura média das plantas foram mais severos durante o desenvolvimento inicial do que no início da frutificação.

\subsection{Número de folhas}

Os números de folhas são apresentados na Tabela 2. No teste de Tukey a 5\% houve diferença significativa entre os tratamentos. Na primeira semana teve uma redução de $47 \%$ das folhas entre o T1 e o T6, igualmente entre o T1 e T5, e na última semana essa redução foi de 64\% entre o T1 e o T5, não podendo comparar na última semana o T1 ao T6 devido ao fato de as plantas não terem sobrevivido ao tratamento. Podendo-se afirmar que o número de folhas da vinagreira é afetado pela salinidade, e que a tolerância da planta a salinidade, quanto ao número de folhas, vai diminuindo com o desenvolvimento da cultura.

Tabela 2: Número de folhas das plantas de vinagreira submetida a diferentes níveis de salinidade da água de irrigação. Sobral, CE, IFCE - Campus de Sobral, 2012.

\begin{tabular}{ccccccc}
\hline \multicolumn{7}{c}{ Níveis de salinidade (dS $\left.\mathbf{~ m}^{-\mathbf{1}}\right)$} \\
\hline DAT & T1 (0,27) & T2 (1,5) & T3 (2,5) & T4 (3,5) & T5 (4,5) & T6 (5,5) \\
\hline $\mathbf{0}$ & $3,4 \mathrm{aCD}$ & $2,8 \mathrm{abCD}$ & $2,6 \mathrm{bcCD}$ & $2,2 \mathrm{cdCD}$ & $1,8 \mathrm{bcCD}$ & $1,8 \mathrm{dCD}$ \\
$\mathbf{7}$ & $4,6 \mathrm{aBC}$ & $3,6 \mathrm{abBC}$ & $4,0 \mathrm{bcBC}$ & $2,2 \mathrm{cdBC}$ & $2,8 \mathrm{bcBC}$ & $2,3 \mathrm{dBC}$
\end{tabular}




\begin{tabular}{ccccccc}
$\mathbf{1 4}$ & $7,6 \mathrm{aAB}$ & $6,6 \mathrm{abAB}$ & $5,0 \mathrm{bcAB}$ & $3,8 \mathrm{cdAB}$ & $5,2 \mathrm{bcAB}$ & $4,3 \mathrm{dAB}$ \\
$\mathbf{2 1}$ & $14,8 \mathrm{Aa}$ & $10,0 \mathrm{abA}$ & $7,8 \mathrm{bcA}$ & $5,4 \mathrm{cdA}$ & $8,8 \mathrm{bcA}$ & $4,7 \mathrm{dA}$ \\
$\mathbf{2 8}$ & $16,8 \mathrm{aA}$ & $10,8 \mathrm{abA}$ & $6,0 \mathrm{bcA}$ & $6,7 \mathrm{cdA}$ & $7,2 \mathrm{bcA}$ & $4,0 \mathrm{dA}$ \\
$\mathbf{3 5}$ & $11,8 \mathrm{aCD}$ & $11,0 \mathrm{abCD}$ & $10,0 \mathrm{bcCD}$ & $0,0 \mathrm{cdCD}$ & $7,0 \mathrm{bcCD}$ & $0,0 \mathrm{dCD}$ \\
$\mathbf{4 2}$ & $12,2 \mathrm{aD}$ & $8,0 \mathrm{abD}$ & $9,0 \mathrm{bcD}$ & $0,0 \mathrm{cdD}$ & $5,0 \mathrm{bcD}$ & $0,0 \mathrm{dD}$ \\
$\mathbf{4 9}$ & $18,2 \mathrm{aCD}$ & $12,0 \mathrm{abCD}$ & $12,0 \mathrm{bcCD}$ & $0,0 \mathrm{cdCD}$ & $6,5 \mathrm{bcCD}$ & $0,0 \mathrm{dCD}$ \\
\hline
\end{tabular}

Médias seguidas pela mesma letra maiúscula na coluna e minúscula na linha não diferem entre si pelo teste de Tukey ao nível de $5 \%$ de probabilidade

Em trabalhos realizados por Silva, Oliveira, Maracajá, Freitas e Mesquita (2008), Lima, Oliveira, Medeiros, Oliveira e Almeida Júnior (2007) e Sales, Eloi, Ribeiro, Moreira e Sales (2011a), avaliando respectivamente os efeitos da salinidade no desenvolvimento da rúcula, do feijão caupi e na cultura da melancia, afirmaram que o número de folhas de cada planta, foram reduzidos à medida que se aumentou o nível de salinidade da água de irrigação.

$\mathrm{O}$ acúmulo de sais no solo pela irrigação com CEa elevada (concentração de $\mathrm{NaCl}$ ) contribuiu negativamente sobre a absorção de água pelas plantas, o que foi determinante para a redução dos processos fotossintéticos e metabólicos da cultura, de forma a provocar redução no número de folhas à medida em que CEa foi acrescida (TRAVASSOS et al., 2012).

\section{4 Área da planta}

A área de uma planta depende do número e do tamanho das folhas, bem como do seu tempo de permanência na planta (MONTEIRO et al., 2005). Na Tabela 3 é observado que houve diferença significativa entre os tratamentos. Enquanto a variação da área da planta na primeira semana entre o T1 e o T6 foi de aproximadamente 89\%, entre o T1 e o T5 apresentou uma redução de $75 \%$, cujo na última semana esse decréscimo da área da planta foi de aproximadamente $80 \%$. Mostrando que houve uma diferença pequena, porém verificando que a área da planta é bastante afetada pelo nível de salinidade da água de irrigação, sobretudo na fase inicial de desenvolvimento.

Tabela 3: Área foliar de plantas de vinagreira submetidas a diferentes níveis de salinidade da água de irrigação. Sobral, CE, IFCE - Campus de Sobral, 2012.

\begin{tabular}{|c|c|c|c|c|c|c|}
\hline \multirow[b]{2}{*}{ DAT } & \multicolumn{6}{|c|}{ Níveis de salinidade $\left(\mathrm{dS} \mathrm{m}^{-1}\right)$} \\
\hline & $\mathrm{T} 1(0,27)$ & $\mathrm{T} 2(1,5)$ & T3 $(2,5)$ & $\mathrm{T4}(3,5)$ & T5 $(4,5)$ & T6 $(5,5)$ \\
\hline 0 & $42,6 \mathrm{aBC}$ & $33,7 \mathrm{abBC}$ & $27,6 \mathrm{bcBC}$ & $11,0 \mathrm{cdBC}$ & $10,6 \mathrm{bcBC}$ & $4,6 \mathrm{dBC}$ \\
\hline 7 & $42,7 \mathrm{aB}$ & $30,2 \mathrm{abB}$ & 32,6 bcB & $9,7 \mathrm{cdB}$ & 16,3 bcB & $5,6 \mathrm{~dB}$ \\
\hline 14 & 107,3 aAB & $78,5 \mathrm{abAB}$ & 42,1 bcAB & $20,0 \mathrm{cdAB}$ & 36,7 bcAB & $13,0 \mathrm{dAB}$ \\
\hline 21 & 205,7 aA & $125,6 \mathrm{abA}$ & 63,3 bcA & $28,7 \mathrm{cdA}$ & 73,8 bcA & $23,9 \mathrm{dA}$ \\
\hline 28 & $238,0 \mathrm{aAB}$ & $134,2 \mathrm{abAB}$ & 52,1 bcAB & $41,5 \mathrm{cdAB}$ & 57,7 bcAB & $27,1 \mathrm{abAB}$ \\
\hline 35 & $155,0 \mathrm{aD}$ & $193,6 \mathrm{abD}$ & $207,0 \mathrm{bcD}$ & $0,0 \mathrm{cdD}$ & 64,6 bcD & $0,0 \mathrm{dD}$ \\
\hline 42 & $157,8 \mathrm{aD}$ & $130,9 \mathrm{abD}$ & $120,5 \mathrm{bcD}$ & $0,0 \mathrm{cdD}$ & 69,9 bcD & $0,0 \mathrm{dD}$ \\
\hline 49 & $277,1 \mathrm{aCD}$ & $158,4 \mathrm{abCD}$ & $175,7 \mathrm{bcCD}$ & $0,0 \mathrm{cdCD}$ & $54,6 \mathrm{bcCD}$ & $0,0 \mathrm{dCD}$ \\
\hline
\end{tabular}


Médias seguidas pela mesma letra maiúscula na coluna e minúscula na linha não diferem entre si pelo teste de Tukey ao nível de $5 \%$ de probabilidade

Os resultados de área foliar obtidos corroboram, com as afirmações de vários autores (OLIVEIRA, OLIVEIRA, MEDEIROS, SOUSA, \& FREIRE, 2010; JAMIL et al., 2007), em que maiores níveis de salinidade proporcionam menor área foliar. Este resultado se deve, provavelmente, às condições adversas, induzindo as plantas desenvolvem formas de adaptação, resultando em alterações bioquímicas e/ou morfológicas. Segundo Tester e Davenport (2003), o decréscimo da área foliar, possivelmente, está relacionado com um dos mecanismos de adaptação da planta ao estresse salino, diminuindo a superfície transpirante.

As folhas da vinagreira possuem duas formas distintas, em função da idade das plantas. As folhas jovens, em expansão, que são bastante irregulares nas extremidades, contudo apresentam-se cordiformes. Estas folhas não perduram por muito tempo. Tem importância apenas nas fases iniciais de desenvolvimento da planta, já que são as primeiras a senescerem.

As folhas seguintes, que começam a nascer por volta de 20 dias após a emergência das plântulas, são denominadas de folhas lobadas, são maiores, com lóbulos bem definidos e mais regulares que as folhas jovens. Monteiro et al., (2005), estudando a área foliar do algodoeiro, verificaram que o mesmo apresenta três tipos de folhas, sendo duas são coincidentes que as observadas em vinagreira. Este fato pode dever-se ao fato das duas espécies serem pertencentes à Família Malvaceae, compartilhando assim características morfológicas em comum.

\subsection{Diâmetro do caule}

Na Tabela 4 encontram-se os valores para o diâmetro do caule, verificando que houve diferença estatística. Nas duas primeiras semanas o diâmetro do caule foi maior no tratamento T5. Ao final do experimento observa-se que um decréscimo de $31 \%$ entre o T1 e o T5, correspondendo a um declínio (na última semana) de $0,37 \mathrm{~mm}$ por aumento unitário da condutividade elétrica da água.

Tabela 4: Diâmetro dos caules das plantas de vinagreira submetidas a diferentes níveis de salinidade da água de irrigação. Sobral, CE, IFCE - Campus de Sobral, 2012.

\begin{tabular}{ccccccc}
\hline \multicolumn{7}{c}{ Níveis de salinidade (dS. $\left.\mathbf{m}^{-\mathbf{1}}\right)$} \\
\hline DAT & T1 (0,27) & T2 (1,5) & T3 (2,5) & T4 (3,5) & T5 (4,5) & T6 (5,5) \\
\hline $\mathbf{0}$ & $1,7 \mathrm{aB}$ & $2,0 \mathrm{abB}$ & $1,9 \mathrm{bcB}$ & $1,9 \mathrm{bcB}$ & $2,1 \mathrm{abB}$ & $1,5 \mathrm{cB}$ \\
$\mathbf{7}$ & $2,6 \mathrm{aAB}$ & $2,6 \mathrm{abAB}$ & $2,5 \mathrm{bcAB}$ & $2,5 \mathrm{bcAB}$ & $2,7 \mathrm{abAB}$ & $2,0 \mathrm{cAB}$ \\
$\mathbf{1 4}$ & $2,9 \mathrm{aA}$ & $3,3 \mathrm{abA}$ & $2,9 \mathrm{bcA}$ & $3,0 \mathrm{bcA}$ & $3,0 \mathrm{abA}$ & $2,1 \mathrm{cA}$ \\
$\mathbf{2 1}$ & $4,2 \mathrm{aA}$ & $3,9 \mathrm{abA}$ & $3,2 \mathrm{bcA}$ & $3,5 \mathrm{bcA}$ & $3,2 \mathrm{abA}$ & $2,8 \mathrm{cA}$ \\
$\mathbf{2 8}$ & $4,3 \mathrm{aAB}$ & $3,5 \mathrm{abAB}$ & $3,3 \mathrm{bcAB}$ & $3,0 \mathrm{bcAB}$ & $3,2 \mathrm{abAB}$ & $3,0 \mathrm{cAB}$ \\
$\mathbf{3 5}$ & $4,5 \mathrm{aC}$ & $4,7 \mathrm{abC}$ & $4,5 \mathrm{bcC}$ & $0,0 \mathrm{bcC}$ & $4,3 \mathrm{abC}$ & $0,0 \mathrm{cC}$ \\
$\mathbf{4 2}$ & $5,9 \mathrm{aC}$ & $5,2 \mathrm{abC}$ & $4,5 \mathrm{bcC}$ & $0,0 \mathrm{bcC}$ & $3,8 \mathrm{abC}$ & $0,0 \mathrm{cC}$
\end{tabular}




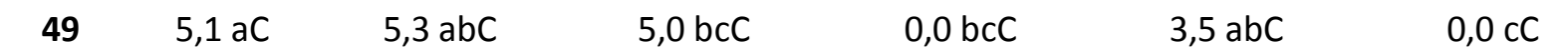

Médias seguidas pela mesma letra maiúscula na coluna e minúscula na linha não diferem entre si pelo teste de Tukey ao nível de $5 \%$ de probabilidade.

Resultado semelhantes foram encontrados por Cavalcanti et al., (2005), em que avaliando a tolerância da mamoneira quanto à salinidade encontrou um declínio de 0,2 $\mathrm{mm}$ $(1,45 \%)$ no diâmetro do caule, por aumento unitário da CEa.

Gurgel et al., (2003), a acompanharem o desenvolvimento de plantas de acerola, verificaram redução linear de 11,01 e 7,64\% no diâmetro do caule, por incremento unitário da salinidade aos 50 e $90 \mathrm{DAE}$, respectivamente. Similarmente ao número de folhas e altura de plantas, a maior influência negativa da salinidade sobre o diâmetro do caule ocorreu aos 50 DAE, evidenciando maior sensibilidade da aceroleira à salinidade na fase inicial de crescimento.

\subsection{Número de hastes}

O número de hastes está ligado à valorização do produto e a formação da planta, refere-se ao aspecto e constituição da planta. Foram consideradas todas as hastes, desde as laterais, como também a haste principal de cada planta. De acordo com a Tabela 5, as plantas até os $52^{\circ}$ dia após a semeadura (DAS) só tinha uma haste, a partir da contagem do $59^{\circ}$ DAP foi observado uma média maior que uma haste por planta. Ao fim do experimento a diferença foi de aproximadamente $44 \%$ entre o número de hastes do T1 ao T5.

Tabela 5: Número de hastes das plantas de vinagreira submetidas a diferentes níveis de salinidade da água de irrigação. Sobral, CE, IFCE - Campus de Sobral, 2012.

\begin{tabular}{ccccccc}
\hline \multicolumn{7}{c}{ Níveis de salinidade (dS $\left.\mathbf{~ m}^{-\mathbf{1}}\right)$} \\
\hline DAT & T1 (0,27) & T2 (1,5) & T3 (2,5) & T4 (3,5) & T5 (4,5) & T6 (5,5) \\
\hline $\mathbf{0}$ & $1,0 \mathrm{aA}$ & $1,0 \mathrm{abA}$ & $1,0 \mathrm{bcA}$ & $1,0 \mathrm{bcA}$ & $1,0 \mathrm{bcA}$ & $1,0 \mathrm{cA}$ \\
$\mathbf{7}$ & $1,0 \mathrm{aA}$ & $1,0 \mathrm{abA}$ & $1,0 \mathrm{bcA}$ & $1,0 \mathrm{bcA}$ & $1,0 \mathrm{bcA}$ & $1,0 \mathrm{cA}$ \\
$\mathbf{1 4}$ & $1,0 \mathrm{aA}$ & $1,0 \mathrm{abA}$ & $1,0 \mathrm{bcA}$ & $1,0 \mathrm{bcA}$ & $1,0 \mathrm{bcA}$ & $1,0 \mathrm{cA}$ \\
$\mathbf{2 1}$ & $1,6 \mathrm{aA}$ & $1,0 \mathrm{abA}$ & $1,0 \mathrm{bcA}$ & $1,0 \mathrm{bcA}$ & $1,0 \mathrm{bcA}$ & $1,0 \mathrm{cA}$ \\
$\mathbf{2 8}$ & $4,6 \mathrm{aA}$ & $2,2 \mathrm{abA}$ & $1,4 \mathrm{bcA}$ & $1,0 \mathrm{bcA}$ & $1,2 \mathrm{bcA}$ & $1,0 \mathrm{cA}$ \\
$\mathbf{3 5}$ & $3,8 \mathrm{aA}$ & $5,0 \mathrm{abA}$ & $4,0 \mathrm{bcA}$ & $0,0 \mathrm{bcA}$ & $4,3 \mathrm{bcA}$ & $0,0 \mathrm{cA}$ \\
$\mathbf{4 2}$ & $6,0 \mathrm{aA}$ & $5,7 \mathrm{abA}$ & $7,0 \mathrm{bcA}$ & $0,0 \mathrm{bcA}$ & $4,0 \mathrm{bcA}$ & $0,0 \mathrm{cA}$ \\
$\mathbf{4 9}$ & $8,0 \mathrm{aA}$ & $7,3 \mathrm{abA}$ & $7,0 \mathrm{bcA}$ & $0,0 \mathrm{bcA}$ & $4,5 \mathrm{bcA}$ & $0,0 \mathrm{cA}$ \\
\hline
\end{tabular}

Médias seguidas pela mesma letra maiúscula na coluna e minúscula na linha não diferem entre si pelo teste de Tukey ao nível de $5 \%$ de probabilidade.

\subsection{Comprimento radicular}

Analisando o comprimento radicular ao nível de $5 \%$ de probabilidade (Tabela 6), observa-se que houve diferença significativa. Verificando que a salinidade decresce o 
comprimento da raiz primária, visto que houve uma redução de $27 \%$ do tamanho radicular, isto quando se compara o T1 ao T5, não sendo possível realizar uma avaliação do T6, pois como mencionado, as plantas neste tratamento não sobreviveram.

Tabela 6: Comprimento radicular das plantas de vinagreira submetidas a diferentes níveis de salinidade da água de irrigação. Sobral, CE, IFCE - Campus de Sobral, 2012.

\begin{tabular}{cc}
\hline Tratamento & PSR \\
\hline T1 & $6,2 \mathrm{a}$ \\
T2 & $4,9 \mathrm{~b}$ \\
T3 & $5 \mathrm{ab}$ \\
T4 & $0 \mathrm{c}$ \\
T5 & $4,5 \mathrm{~b}$ \\
T6 & $0 \mathrm{c}$ \\
\hline
\end{tabular}

As médias seguidas pela mesma letra não diferem estatisticamente entre si. Foi aplicado o Teste de Tukey $(p \leq 0,05)$.

Em um trabalho realizado por Freitas, Amaro Filho e Moura Filho (2006), ao avaliarem o efeito da salinidade na germinação e desenvolvimento de plantas de melão constataram que a salinidade afetou drasticamente o desenvolvimento das plantas de meloeiro em relação ao comprimento de raiz, altura das plantas e consequentemente à massa fresca e seca das plantas.

A diminuição no número de raízes acarreta diminuição na capacidade de absorção de água e nutrientes pela planta, diminuindo, consequentemente a quantidade de nutrientes disponíveis para serem translocados aos demais órgãos, ocasionando menor crescimento e desenvolvimento da planta (BENITEZ, 2008).

\subsection{Peso seco da parte aérea}

Em relação ao peso seco da parte aérea (Tabela 7) houve diferença significativa entre os tratamentos. Apresentando maior resultado no T1, tratamento testemunha, cujo observase que este diferiu estatisticamente apenas do T4 e T6, que são os tratamentos que não se apresentam resultados positivos, pois nestes tratamentos as não sobreviveram.

Tabela 7: Peso seco da parte aérea das plantas de vinagreira submetidas a diferentes níveis de salinidade da água de irrigação. Sobral, CE, IFCE - Campus de Sobral, 2012.

\begin{tabular}{cc}
\hline Tratamento & PSR \\
\hline T1 & $2,52 \mathrm{a}$ \\
T2 & $2,05 \mathrm{a}$ \\
T3 & $1,28 \mathrm{ab}$ \\
T4 & $0,00 \mathrm{~b}$ \\
T5 & $1,07 \mathrm{ab}$ \\
T6 & $0,00 \mathrm{~b}$ \\
\hline
\end{tabular}


As médias seguidas pela mesma letra não diferem estatisticamente entre si. Foi aplicado o Teste de Tukey $(p \leq 0,05)$.

A menor absorção de água pelas sementes atua reduzindo a velocidade dos processos fisiológicos e, com isso, as plântulas resultantes, apresentam menor desenvolvimento, caracterizado por menores comprimentos da plântula e menor acúmulo de peso de massa seca (TORRES, 2007). Enquanto que segundo Taiz e Zeiger (2006), um alto nível salino reduz a taxa de assimilação metabólica, a atividade de enzimas responsáveis pela respiração e fotossíntese, restringindo assim, a obtenção de energia para o crescimento e diferenciação das células em tecidos, reduzindo consequentemente, o alongamento do eixo embrionário e a produção de massa seca.

\subsection{Peso seco do sistema radicular}

De acordo com a Tabela 8 houve diferença significativa entre os tratamentos. Porém o maior valor foi encontrado no T3, onde este não diferiu do T1, tratamento testemunha.

Tabela 8: Peso seco radicular das plantas de vinagreira submetidas a diferentes níveis de salinidade da água de irrigação. Sobral, CE, IFCE - Campus de Sobral, 2012.

\begin{tabular}{cc}
\hline Tratamento & PSR \\
\hline T1 & $0,364 \mathrm{a}$ \\
T2 & $0,319 \mathrm{ab}$ \\
T3 & $0,393 \mathrm{a}$ \\
T4 & $0,000 \mathrm{c}$ \\
T5 & $0,119 \mathrm{bc}$ \\
T6 & $0,000 \mathrm{c}$ \\
\hline
\end{tabular}

As médias seguidas pela mesma letra não diferem estatisticamente entre si. Foi aplicado o Teste de Tukey $(p \leq 0,05)$.

No trabalho realizado por Kawavata, Fois, Coppo e Alves Neto (2017) estes observaram que conforme houve o aumento da concentração de potássio, apresentou elevação na condutividade elétrica da solução do solo, no entanto houve diminuição no teor da massa seca das raízes. Alguns trabalhos relatam alterações anatômicas que os sais podem promover em raízes de pinhão-manso. Melo, Cunha, Pereira, Willadino e Ulisses (2011) comprovaram em seu trabalho que quando as raízes de pinhão-manso são submetidas ao estresse salino, apresentam maior lignificação das células xilemáticas e endodérmicas e redução no diâmetro e no número de elementos de vaso; além do mais, evidencia-se a presença de estrias de Caspary, contendo maior quantidade de lignina, com maior fortalecimento a barreira apoplástica para o fluxo de íons e de água (CASTRO, PEREIRA, \& PAIVA 2009), sendo quanto maior a deposição de lignina mais difícil se torna a perda radial de oxigênio (COLMER, MUNNS, \& FLOWERS, 2005), elemento fundamental no processo de exclusão de sódio em plantas submetidas ao estresse salino (MELO et al., 2011). 
Para Gurgel et al., (2003), o fato das sementes serem pequenas e portanto, com poucas reservas, utilizam-nas, inicialmente, no crescimento da parte aérea para garantir melhores condições de fotossíntese passando, em seguida, a incrementar a massa radicular, visando acelerar a absorção de água devido ao baixo potencial osmótico, uma vez que as raízes foram menos afetadas com maior tempo de avaliação.

\subsection{Condutividade elétrica e Potencial osmótico do substrato}

Os resultados demonstram que conforme houve um aumento da condutividade elétrica da água, teve-se um aumento da condutividade elétrica da solução do solo. Os resultados foram 0,$8 ; 1,2 ; 2,1 ; 3,4 ; 4,2$ e 4,8 respectivamente para os tratamentos T1, T2, T3, T4, T5 e T6. Na Figura 1, observa-se o potencial osmótico da solução do solo ao final do experimento, constata-se que quanto maior o nível de salinidade, maiores serão a concentração de sais no solo e a força de retenção de água no mesmo.

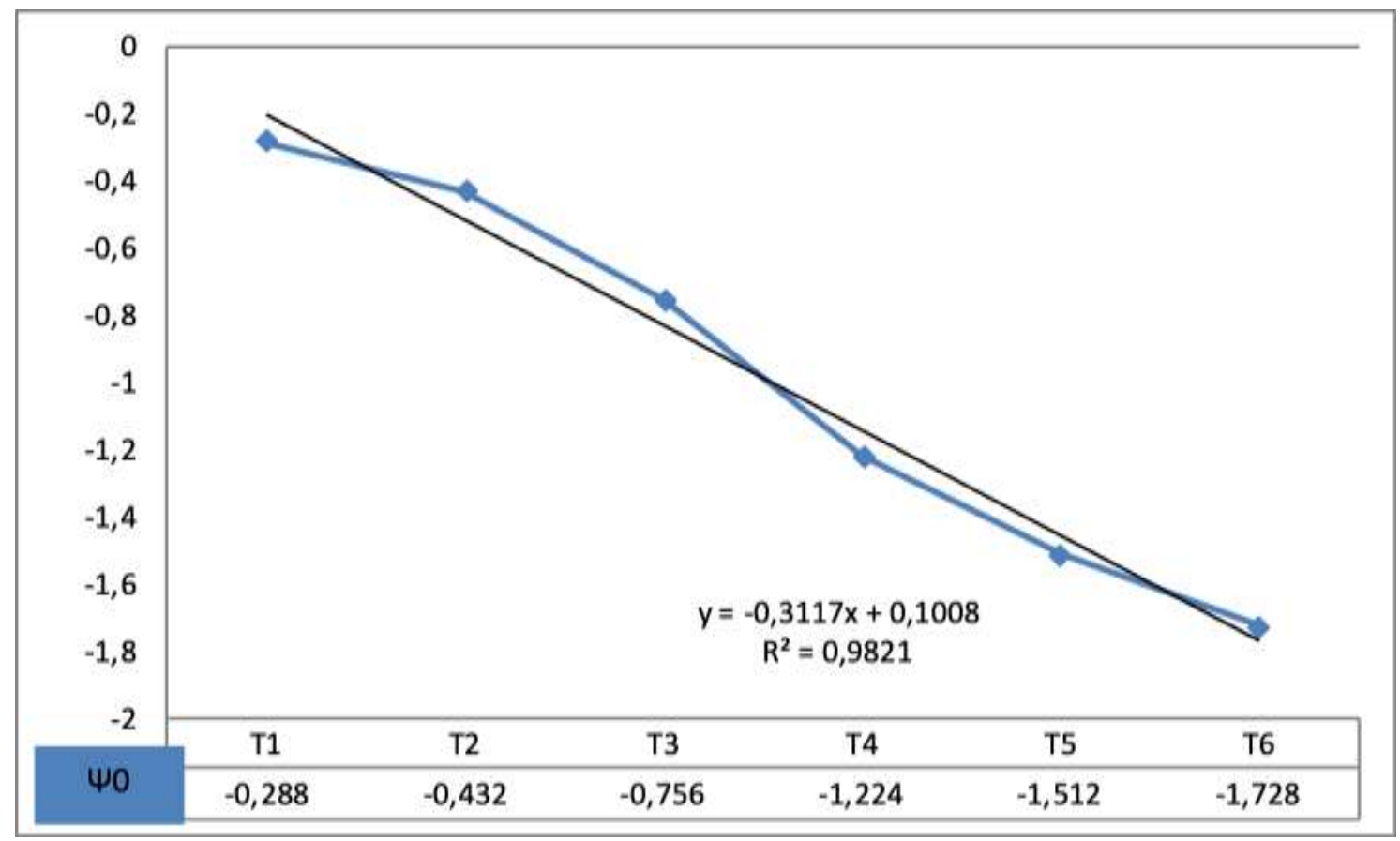

Figura 1: Regressão linear do potencial osmótico do solo em função do aumento da salinidade da água de irrigação.

O potencial osmótico é um dos responsáveis por reter a água no solo, não permitindo que a planta absorva água o necessário para o seu desenvolvimento e vigor, interferindo assim a germinação (porcentagem de germinação, índice de velocidade de germinação, tempo médio de germinação e primeira contagem da germinação), como também o desenvolvimento da cultura (altura da planta, número de folhas, diâmetro do caule, área da planta, peso seco e verde), mas o grau de interferência vai depender do potencial osmótico como também da tolerância da planta. 
O aumento da pressão osmótica (PO) causado pelo excesso de sais solúveis poderá atingir um nível em que as plantas não terão forças de sucção suficiente para superar esse (PO) e, em consequência, a planta não irá absorver água, mesmo de um solo aparentemente úmido (seca fisiológica). Dependendo do grau de salinidade, a planta, em vez de absorver, poderá até perder a água que se encontra no seu interior (GHEYl et al., 2010).

Em condições salinas, ocorre uma redução na disponibilidade de água, ou seja, com o acúmulo de sais no solo, o potencial total da água sofre uma redução, ocasionada pela contribuição do potencial osmótico (MOTA, BOAS, \& SOUSA, 2006).

Resultados semelhantes foram encontrados em trabalhos realizado por Sales et al., (2011abc), ao observarem o potencial osmótico em solo irrigação com as mesmas concentrações salinas, nas culturas de melancia e erva doce.

\section{CONCLUSÕES}

Com base nos resultados acima, conclui-se que, com a elevação da concentração de sais na água de irrigação, observou-se uma redução no desenvolvimento inicial das mudas de vinagreira, esta redução foi observada em todos os parâmetros, altura da planta, número de folhas, área da planta, diâmetro do caule, número de hastes, comprimento radicular, peso seco da parte aérea e radicular. Além de observar uma elevação no potencial osmótico do solo, cuja interação das maiores concentrações de sais com as mais avançadas épocas de avaliação apresentou morte das plantas observadas.

\section{REFERÊNCIAS BIBLIOGRÁFICAS}

BERNARDO, S.; SOARES, A. A.; MANTOVANI, E. C. (2006). Manual de irrigação. 8.ed. Viçosa, MG: UFV, 2006. 625p.

BENITEZ, L. C. (2008). Tolerância à salinidade avaliada em genótipos de arroz, cultivados ex vitro e in vitro. Pelotas - RS. 110p. Dissertação (Mestrado em Fisiologia Vegetal) Universidade Federal de Pelotas.

CARDOSO, M. O. (1997). Hortaliças não-convencionais da Amazônia. Brasília: Embrapa-SPI

CASTRO, E. M.; PEREIRA, F. J.; PAIVA, R. (2009). Histologia vegetal: estrutura e função de órgãos vegetativos. Lavras: Editora UFLA. 234p.

CASTRO, N. E. A., PINTO, J. E. B. P., CARDOSO, M. G., MORAIS, A. R., BERTOLUCCI, S. K. V., SILVA, F. G., DELÚ FILHO, N. (2004). Planting time for maximization of yield of vinegar plant calyx (Hibiscus sabdariffa L.). Ciência e Agrotecnologia, 28(3), 542-551.

CAVALCANTI, M. L. F.; FERNANDES, P. D.; GHEYI, H. R.; BARROS JÚNIOR, G.; SOARES, F. A. L.; SIQUEIRA. E. da C. (2005). Tolerância da mamoneira BRS 149 à salinidade germinação e características de crescimento. Revista Brasileira de Engenharia Agricola e Ambiental, 9(suplemento), 57-61. 
COLMER, T. D.; MUNNS, R.; FLOWERS, T. J. (2005). Improving salt tolerance of wheat and barley: future prospects. Australian Journal of Experimental Agriculture. 45(11), 14251443.

DIAS, N. S.; DUARTE, S. N.; MEDEIROS, J. F.; TELES FILHO, J. F. (2006). Salinidade e manejo da fertirrigação em ambiente protegido. I: efeitos sobre o crescimento de meloeiro. Revista Irriga, Botucatu, 11(2), 208-218.

FAO. (2011). The State of the World's Land and Water Resources: managing systems at risk. London: Earthscan.

FREIRE, A. L. O.; SOUSA FILHO, G. M.; MIRANDA, J. R. P.; SOUTO, P. C.; ARAÚJO, L. V. C. (2010). Crescimento e nutrição mineral do nim (Azadirachta indica A. Juss.) e cinamomo (Melia azedarach Linn.) submetidos à salinidade. Revista Ciência Florestal, Santa Maria, 20(2), 207-215.

FREITAS, R. S.; AMARO FILHO, J.; MOURA FILHO, E. R. (2006). Efeito da salinidade na germinação e desenvolvimento de plantas de meloeiro. Revista verde. Mossoró - RN. 1(2), 113-121.

GHEYI, H. R.; DIAS, N. S.; LACERDA, C. F. (2010). Manejo da salinidade na agricultura: Estudos básicos e aplicados. Fortaleza, INCT Sal, 472p.

GURGEL, M. T.; FERNANDES, P. D.; SANTOS, F. J. S.; GHEYI, H. R.; BEZERRA, I. L.; NOBRE, R. G. (2003). Estresse salino na germinação e formação de porta-enxerto de aceroleira. Revista Brasileira de Engenharia Agrícola e Ambiental, Campina Grande, 7(1), 31-36.

JAMIL, M.; REHMAN, S.; LEE, K. J.; KIM, J. M.; KIM, H. S.; RHA, E. S. (2007). Salinity reduced growth PS2 photochemistry and chlorophyll content in radish. Scientia Agricola, 64(2), 111-118.

KAWAVATA, C. K. H.; FOIS, F. A. F.; COPPO, J. C.; ALVES NETO, A. (2017). Influência de doses e de duas fontes de potássio no sistema radicular do milho e na condutividade elétrica do solo. Investigación Agraria, 19(1), 28-34.

LIMA, C. J. G. S.; OLIVEIRA, F. A.; MEDEIROS, J. F.; OLIVEIRA, M. K. T.; ALMEIDA JÚNIOR, A. B. (2007). Resposta do feijão caupi à salinidade da água de irrigação. Revista Verde (Mossoró - RN - Brasil), 2(2), 79-86.

LIRA, J. V.; ELOI, W. M.; SALES. M. A. L.; RIBEIRO, A. A.; NOGUEIRA, S. L. (2011). Efeito de diferentes níveis de salinidade na germinação de sementes de manjericão. XXXIII Congresso Brasileiro de Ciência do Solo, Uberlândia - MG.

LORENZI, H.; SOUZA, H. M. (2000). Plantas ornamentais no Brasil: arbustivas, herbáceas e trepadeiras. 2.ed. Nova Odessa: Instituto Plantarum, 1088p.

MARTINS, M. A. S. (1985). Vinagreira (Hibiscus sabdariffa L.) uma riqueza pouco conhecida. São Luiz: Emapa, 12p. 
MEDEIROS, J. F.; SILVA, M. C. C.; SARMENTO, D. H. A.; BARROS, A. D. (2007). Crescimento do meloeiro cultivado sob diferentes níveis de salinidade, com e sem cobertura do solo Revista Brasileira de Engenharia Agrícola e Ambiental, 11(3), 248-255.

MELLO, J. L. P. (2009). Drenagem agrícola. Departamento de Engenharia, Universidade Federal Rural do Rio de Janeiro, 99p.

MELO, G. M.; CUNHA, P. C.; PEREIRA, J. A. F., WILLADINO, L.; ULISSES, C. (2011). Alterações anatômicas em folhas e raízes de Jatropha curcas $\mathrm{L}$. cultivadas sob estresse salino. Revista Ciência Agronômica, 42(3), 670-674.

MONTEIRO, J. E. B. A.; SENTELHAS, P. C.; CHIAVEGATO, E. J.; GUISELINI, C.; SANTIAGO, A. V.; PRELA, A. (2005). Estimação da área foliar do algodoeiro por meio de dimensões e massa das folhas. Bragantia, Campinas, 64(1), 15-24.

MOTA, P. R. L. D.; BOAS, R. L. V.; SOUSA, V. F. (2006). Concentração de sais da solução avaliada pela condutividade elétrica na zona radicular do crisântemo sob irrigação por gotejamento. Irriga, Botucatu, 11(4), 532-542.

OLIVEIRA, F. R. A.; OLIVEIRA, F. A.; MEDEIROS, J. F.; SOUSA, V. F. L.; FREIRE, A. G. (2010). Interação entre salinidade e fósforo na cultura do rabanete. Revista Ciência Agronômica, 41(4), 519-526.

RICHARDS, L. A. (1954). Diagnosis and improvement of saline and alkali soils. USDA Agricultural handbook 60. Washington: U.S: Department of Agriculture.

SALES, M. A. L.; ELOI, W. M.; RIBEIRO, A. A.; MOREIRA, F. J. C.; SALES, F. A. L. (2011a) Crescimento inicial da melancia em função dos níveis de salinidade. VI Congresso de Pesquisa e Inovação da Rede Norte e Nordeste de Educação Tecnológica. Natal - RN.

SALES, M. A. L.; ElOI, W. M.; RIBEIRO, A. A.; SALES, F. A. L.; NOGUEIRA, S. L. (2011b). Germinação das sementes de girassol em resposta a diferentes níveis de salinidade. $\mathrm{X}$ Encontro de Pesquisa e Pós-graduação - XENPPG / X Encontro de Iniciação Cientifica e Tecnológicas / X ENICIT / V Simpósio de Inovação Tecnológica - V SIMPIT do IFCE. Fortaleza-CE.

SAlES, M. A. L.; MOREIRA, F. J. C.; ElOI, W. M.; RIBEIRO, A. A.; SALES, F. A. L. (2011c). Desenvolvimento inicial de plântulas de erva doce (Foeniculum vulgare Mill). VI Congresso de Pesquisa e Inovação da Rede Norte e Nordeste de Educação Tecnológica. Natal - RN.

SILVA, A. B.; WIEST, J. M.; CARVALHO, H. H. C. (2016). Compostos químicos e atividade antioxidante analisados em Hibiscus rosa-sinensis $L$. (mimi-de-vênus) e Hibiscus syriacus $L$. (hibisco-da-síria). Brazilian Journal of Food Technology. Campinas. 19, 1-9.

SILVA, A. L.; NASCIMENTO, M. N.; TANA, T. T.; OLIVEIRA, U. C.; LIMA, J. C. (2017). Efeito da salinidade da água de irrigação na produção de alface crespa. Enciclopédia biosfera. 14(26), 328. 
SILVA, J. K. M. OLIVEIRA, F. A.; MARACAJÁ, P. B.; FREITAS, R. S.; Mesquita, L. X. (2008). Efeito da salinidade e adubos orgânicos no desenvolvimento da rúcula. Revista Caatinga, Mossoró, 21(5), 30-35.

SOBOTA, J. F.; PINHO. M. G.; OLIVEIRA, V. B. (2016). Perfil físico-químico e atividades antioxidante do cálice de espécie Hibiscus sabdariffa L. a partir do extrato aquoso e alcoólico obtidos por infusão e decocto. Revista fitos. 10(1), 33-46.

TAIZ, L.; ZEIGER, E. (2006). Fisiologia vegetal. Porto Alegre: Artmed. 719p.

TESTER, M.; Davenport, R. (2003). $\mathrm{Na}^{+}$tolerance and $\mathrm{Na}^{+}$transport in higher plants. Annals of Botany, 91, 503-527.

TORRES, S. B. (2007). Germinação e desenvolvimento de plântulas de melancia m função da salinidade. Revista Brasileira de sementes, 29(3), 77-82.

TRAVASSOS, K. D.; GHEYI, H. R.; SOARES, F. A. L.; BARROS, H. M. M.; DIAS, N. S.; UYEDA, C. A.; SILVA, F. V. (2012). Crescimento e desenvolvimento de variedades de girassol irrigado com água salina. Revista Irriga, Botucatu, p.324 - 339.

VIZZOTO, M.; PEREIRA, M. C. (2008). Hibisco: do uso ornamental ao medicinal. Artigo em Hypertexto. Disponível em: <http://www.infobibos.com/Artigos/2008_4/hibisco/index.htm>. Acesso em: 20 de janeiro de 2012. 